\title{
Soil particle and moisture-related factors determine landward distribution of bacterial communities in a lateral riverside continuum of the Xilin River Basin
}

\author{
Jingli Yu ${ }^{1, *}$, Jingjing Xia ${ }^{1}$, Qiaoli Ma ${ }^{1}$, Chi Zhang ${ }^{1}$, Ji Zhao ${ }^{1}$, Xininigen Tanggood ${ }^{2}$, Yunfeng Yang ${ }^{3, *}$ \\ 1 Ministry of Education Key Laboratory of Ecology and Resource Use of the Mongolia Plateau, Inner Mongolia Key Laboratory of \\ Environmental Pollution Control \& Waste Resource Reuse, School of Ecology and Environment of Inner Mongolia University, Hohhot \\ 010021, China \\ 2 Ministry of Agriculture Key Laboratory of Clinical Diagnosis and Treatment Technology in Animal Disease, College of Veterinary Medicine \\ of Inner Mongolia Agricultural University, Hohhot 010018, China \\ 3 State Key Joint Laboratory of Environment Simulation and Pollution Control, School of Environment, Tsinghua University, Beijing 100084, \\ China
}

\section{H I G H L I G H T S}

- The riverbed-oxbow lake bed-floodplainterrace continuum.

- Dominant bacteria substantially differed along the continuum.

- The highest bacterial diversity in floodplains and the lowest in terraces.

- Soil particle and moisture-related factors determine bacterial communities.

\section{ARTICLE INFO}

Article history:

Received January 21, 2021

Revised May 25, 2021

Accepted May 25, 2021

Keywords:

Biogeography

Landward distribution

Lateral riverside continuum

Hydrologic connectivity and disconnectivity

Bacterial communities

Combined environmental factors
GRAPHICAL ABSTRACT

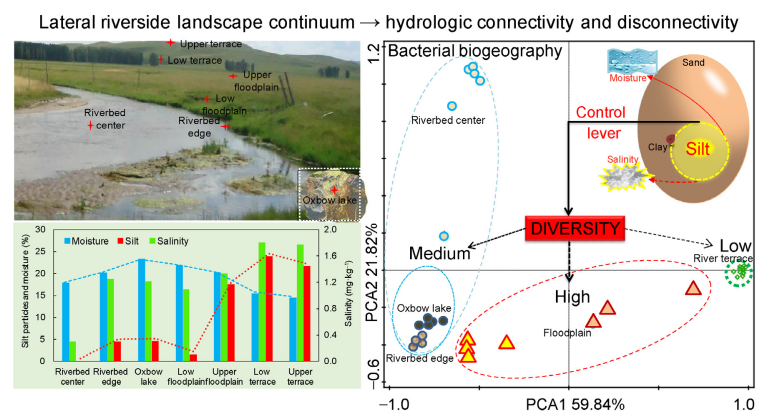

A B S T R A C T

Continuous landscape components along the lateral riverside are affected by both hydrologic connectivity and disconnectivity. In recent years, anthropogenic activities and climate changes have caused wetland shrinkage and land degradation along the lateral riverside of many arid and semiarid regions. Since microorganisms are major drivers of soil biochemical cycling, it is essential to examine soil microbial communities along the lateral landscape continuum to understand their ecosystem functioning and predict future land changes. Here, we collected samples along a lateral riverbed center-riverbed edge-oxbow lake-floodplain-terrace continuum (i.e., landward distribution) in the Xilin River Basin, Inner Mongolia, China. The floodplain had the highest microbial diversity and heterogeneity, with Bacteroidetes, $\beta$ - and $y$-Proteobacteria being the most abundant taxa. In contrast, the terrace had the lowest microbial diversity and heterogeneity, with Acidobacteria, Actinobacteria, Verrucomicrobia, Gemmatimonadetes, and a-Proteobacteria as the most abundant taxa. Silt particle, salinity, and moisture were the most influential factors for landward variation of bacterial communities along the riverside continuum. Altogether, we demonstrate that dominant bacterial lineages, soil particles, and moisture-related factors are valuable indicators of this continuum, which can be leveraged for the early prediction of drought-induced wetland shrinkage and grassland desertification.

๑) Higher Education Press 2021

\footnotetext{
* Corresponding authors

E-mail address: hot-yjl@163.com (J. Yu); yangyf@tsinghua.edu.cn (Y. Yang)
} 


\section{Introduction}

Hydrologic connectivity and disconnectivity are important for understanding how the movement of water influences landscape-scale processes (Bracken et al., 2013; Gay et al., 2016). The riverbed center, riverbed edge, oxbow lake, floodplain, and terrace are continuous components of a riverside landscape, which are influenced mostly by the lateral (from the riverbed to floodplain and river terrace) and vertical (surface runoff to groundwater) movement of water. Hydrologic connectivity and disconnectivity emerge from interactions of topographic, climatic, geologic, biotic, and anthropogenic controls (Leibowitz et al., 2018). In recent years, the Xilin River Basin in Inner Mongolia of China has witnessed considerable changes in the landscape, including wetland shrinkage and grassland desertification (Tong et al., 2004). Therefore, assessing the lateral riverside landscape from the riverbed to floodplain and river terrace in the Xilin River Basin is critical for elucidating the mechanisms of landscape changes and improving knowledge-based management to prevent future land degradation.

Most studies in the Xilin River Basin have focused on aboveground vegetation, showing that precipitation and paleoclimate are influential for community composition and plant function (Bai et al., 2000; Shi et al., 2020). In sharp contrast, little is known about soil bacterial communities, which play critical roles in regulating ecosystem processes and driving biogeochemical cycles (Fierer et al., 2012; Yang et al., 2013). Given the importance of hydrologic connectivity and disconnectivity, one might expect that soil water content (i.e., moisture) will be a major driver of soil microbial communities in the lateral riverside landscape, as witnessed for aboveground vegetation of the Xilin River Basin. If true, it differs from previous findings that soil bacterial communities are mainly shaped by $\mathrm{pH}$ at global and regional scales (Fierer and Jackson, 2006; Shen et al., 2013) and salinity is a major factor driving the bacterial communities in aquatic ecosystems (Shen et al., 2018; Zhang et al., 2019).

To date, there is barely any soil ecology study focusing on a landscape continuum linking to hydrologic connectivity and disconnectivity. To address it, we collected samples along a geomorphological gradient from the riverbed to floodplain and river terrace in the Xilin River Basin. Our main hypothesis is that bacterial communities in those samples are mainly shaped by soil moisture. However, our results only partially support the hypothesis.

\section{Materials and methods}

\subsection{Study area and sample collection}

Our study area is the middle reach of the Xilin River Basin, located in Inner Mongolia, China (Fig. S1). It spans from $43^{\circ} 39^{\prime} \mathrm{N}$ to $44^{\circ} 36^{\prime} \mathrm{N}$ and from $115^{\circ} 33^{\prime} \mathrm{E}$ to $117^{\circ} 28^{\prime} \mathrm{E}$, covering an area of $3900 \mathrm{~km}^{2}$ with an elevation between 900 and
$1400 \mathrm{~m}$ a.s.I. The area is influenced by a temperate zone with a semi-arid continental monsoon climate and four distinct seasons, characterized by sufficient sunlight, an average annual precipitation of $296.3 \mathrm{~mm}$ and a mean annual temperature of $2.6^{\circ} \mathrm{C}$ in recent 60 years. The highest monthly temperature is in July $\left(22.4^{\circ} \mathrm{C}\right)$, and the lowest monthly temperature is in January $\left(-21.0^{\circ} \mathrm{C}\right)$ (Wu et al., 2021).

We took samples along a lateral riverside continuum in (1) riverbed center, (2) riverbed edge, (3) oxbow lake, (4) low floodplain, (5) upper floodplain, (6) low terrace, and (7) upper terrace (i.e., landward distribution). There is no visible plant in the submerged riverbed center with the water depth of 0.25 $0.45 \mathrm{~m}$. The submerged riverbed edge is dominated by Juncellus serotinus with the water depth of $0.45-0.65 \mathrm{~m}$. The submerged oxbow lake is dominated by unclassified phytoplankton with the water depth of $0.55-0.85 \mathrm{~m}$. The floodplain soils are dominated by Juncus effusus and Potentilla anserine, which are mainly characterized by coarse grainsized $(>2 \mathrm{~mm}$ ) sand with poor organic matters. The terrace soils from the typical steppe are dominated by Leymus chinensis and Stipa grandis, characterized by fine-grained silt clay with rich organic matters. Our study area is open for free grazing by livestock.

In early July 2017, the high mean daily temperature at sampling sites was about $18.5^{\circ} \mathrm{C}$. A total of 34 samples were collected from the riverbed center (R1 with 6 samples), riverbed edge (R2 with 4 samples), oxbow lake (R3 with 5 samples), low floodplain (F1 with 4 samples), upper floodplain (F2 with 3 samples), low terrace (T1 with 6 samples) and upper terrace (T2 with 6 samples) The width and length of per geomorphological unit ranged from $1 \mathrm{~m}$ to $10 \mathrm{~m}$ and from $1 \mathrm{~km}$ to $5.5 \mathrm{~km}$, respectively. The distance between riverbed and floodplain ranged from $5 \mathrm{~m}$ to $500 \mathrm{~m}$, while the distance between floodplain and terrace ranged from $15 \mathrm{~km}$ to $20 \mathrm{~km}$. To minimize soil heterogeneity, each sample was a composite sample formed by homogenizing 15 soil cores of $0-10 \mathrm{~cm}$ in depth and $5 \mathrm{~cm}$ in diameter. All samples were collected with a sterilized motor-driven column cylinder. The samples were sieved by $2 \mathrm{~mm}$ sieves to homogenize them and remove coarse roots and visible stones. A portion of each sample was lyophilized at $-80^{\circ} \mathrm{C}$ for DNA extraction. Another portion was stored at $4^{\circ} \mathrm{C}$ for ammonia nitrogen and nitrate nitrogen measurements. The rest was air-dried at the room temperature before determining soil physicochemical properties.

\subsection{Measurements of soil physicochemical properties}

We measured particle size distribution (sand, silt, and clay), moisture, salinity, $\mathrm{pH}$, concentrations of ammonia and nitrate, total organic carbon (TOC), total nitrogen (TN), and total phosphorus (TP). The sand-silt-clay particle contents were determined by an S3500 analyzer (Microtrac Inc, Montgomeryville, PA, USA). The moisture content was determined by oven-drying to constant weight at $105^{\circ} \mathrm{C}$. $\mathrm{pH}$ and salinity were measured in the supernatant with a glass electrode after the sub-samples were suspended at a soil-to-deionized water 
ratio of 1:2.5 using a MultiLab 540 (WTW GmbH, Weilheim, BW, Germany). The contents of TOC, TN, and TP were measured after grinding sub-samples to a size of $0.15 \mathrm{~mm}$ in a ball mill employing an automatic element analyzer (Elementar Vario EL Bundy III, Hanau, HE, Germany) while the contents of ammonia nitrogen and nitrate nitrogen were detected by an ion chromatograph IC2010 (Tosoh Inc., Tokyo, Japan) equipped with a SuperlC-AZ column (Tosoh Inc., Tokyo, Japan).

2.3 DNA extraction, 16S rRNA gene amplification, and Illumina sequencing

Total microbial DNA from soil samples was extracted based on the FastDNA Spin Kit for Soil (MP Biomedicals, Heidelberg, BW, Germany) and purified by the GeneClean Spin Kit (MP Biomedicals, Heidelberg, BW, Germany), following the manufacturer's protocol. DNA quality was detected based on $260 / 280$ and $260 / 230$ ratios using an ND-2000 UV-Vis Spectrophotometer (NanoDrop Technologies Inc., Wilmington, DE, USA), while DNA concentrations were quantified by Quant-iT PicoGreen dsDNA assay (Invitrogen, Carlsbad, CA, USA).

Each sample with different barcodes was amplified in triplicate using a Gene Amp PCR-System ${ }^{\circledR} 9700$ (Applied Biosystems, Foster, CA, USA). PCR primers 338F (5'ACTCCTACGGGAGGCAGCA-3') and 806R (5'-GGACTACHVGGGTW-TCTAAT-3') targeted the V3-V4 regions of the 16S rRNA gene (Wang et al., 2017). The $20 \mu \mathrm{L}$ of standard PCR reaction mixture contained $1 \mu \mathrm{L}$ of genomic DNA (10 $\mathrm{ng})$ as a template, $5 \mu \mathrm{M}$ forward or reverse primer $(0.4 \mu \mathrm{L}), 2.5 \mathrm{mM}$ dNTPs $(2 \mu \mathrm{L})$, FastPfu DNA Polymerase $(0.4 \mu \mathrm{L})$, and $5 \times$ FastPfu Buffer $(4 \mu \mathrm{L})$. PCR programs employed an initial denaturation at $95^{\circ} \mathrm{C}$ for $2 \mathrm{~min}$, followed by 25 cycles of denaturation at $95^{\circ} \mathrm{C}$ for $30 \mathrm{~s}$, annealing at $55^{\circ} \mathrm{C}$ for $30 \mathrm{~s}$, and extension at $72^{\circ} \mathrm{C} 30 \mathrm{~s}$, with a final extension step at $72^{\circ} \mathrm{C}$ for $5 \mathrm{~min}$. The triplicate PCR products were combined into one sample and purified by the QIAquick Gel Extraction Kit (Qiagen, Valencia, CA, USA) and analyzed on a 2100 Bioanalyzer with High Sensitivity DNA Chips (Agilent Technologies, Waldbronn, BW, Germany). All amplicons were quantified by Quant-iT PicoGreen dsDNA assay (Invitrogen, Carlsbad, CA, USA) and then pooled at equal concentrations and sequenced on the Illumina MiSeq platform at Biomarker Technologies Corporation in Beijing of China. Illumina sequencing and data analyses were performed.

\subsection{Raw sequencing data processing and statistical analyses}

MG-RAST API (http://api.metagenomics.anl.gov/api.html) was employed to process raw reads, with the default quality filtering by Trimmomatic. Paired-end reads were merged by Flash. Chimera was detected by UCHIME for quality control. High-quality sequences were processed to generate operational taxonomic units (OTUs) by UCLUST at a $97 \%$ sequence similarity. The taxonomic assignment of representative sequence per OTU was aligned by the RDP classifier (version 2.2) at phylum, class, order, family, genus, and species levels with the default value of 0.8 as confidence threshold (Weese and Jalali, 2014). The $\alpha$-diversity indices were calculated using Mothur version v.1.30 (http://www.mothur.org).

The analysis of variance (ANOVA), Pearson's correlations, and the false discovery rate (FDR) with adjusted $P$-value were performed by SPSS Statistics 24. Unweighted unifrac principal coordinates analyses (PCoA), and unweighted pair group method with arithmetic averages (UPGMA) clustering, adonis, random forest analysis (RFA), and other analyses were performed using $R$ language 3.5.3. The redundancy analyses (RDA) and variation partitioning analyses (VPA) with the Monte Carlo test with 499 permutations were performed using the Canoco for Windows 4.5 (Biometris, Wageningen, GLD, Netherlands). The generalized histogram and line chart analyses were performed by Microsoft Excel 2010. $P$-values less than 0.05 were regarded as significant differences in all statistical tests. All data are available in NCBI accession number SRR8835404-SRR8835437.

\section{Results}

\subsection{The physicochemical properties of soil samples}

The sample map is shown in Fig. 1, wherein riverbed center, riverbed edge, and oxbow lake represent aquatic habitats, low and upper floodplains represent hygric habitats, and low and upper terraces represent xeric habitats. Silt and clay particles ranged from $0.03 \%$ in the riverbed center to $23.98 \%$ in the upper terrace. Sand particles ranged from $61.77 \%$ in the upper terrace to $99.97 \%$ in the riverbed center (Table S2). Soils originating from the riverbed center and floodplains were mainly characterized by coarse sedimentary sand particles. Soils originating from the riverbed edge and oxbow lake alluviums were mainly characterized by fine silt and clay particles rich in ammonia and organic matters (Table S1 and Table S2). The river terrace was typically the chestnut soils characterized by silt and clay particles (Table S1 and Table S2). As a result, silt and clay particles increased while sand particles decreased along the lateral riverside continuum (Fig. 2). Compared to other sites, the low and upper floodplains were considerably different in particle fractions (ANOVA, $P<0.05$, Fig. 2). Soil moisture decreased from $23.34 \%$ in oxbow lake to $14.51 \%$ in the upper terrace, while salinity increased from $0.30 \mathrm{mg} \mathrm{kg}^{-1}$ in the riverbed center to $1.81 \mathrm{mg} \mathrm{kg}^{-1}$ in the low terrace (Table S2 and Fig. 2).

\subsection{Bacterial communities}

A total of 1733272 high-quality reads with an average fragment length of 459 bp were obtained from 34 soil samples, which were subsequently grouped into 43830 OTUs at a $97 \%$ sequence similarity cutoff. The $\alpha$-diversity was the highest in the oxbow lake and floodplains, and the lowest in the riverbed 


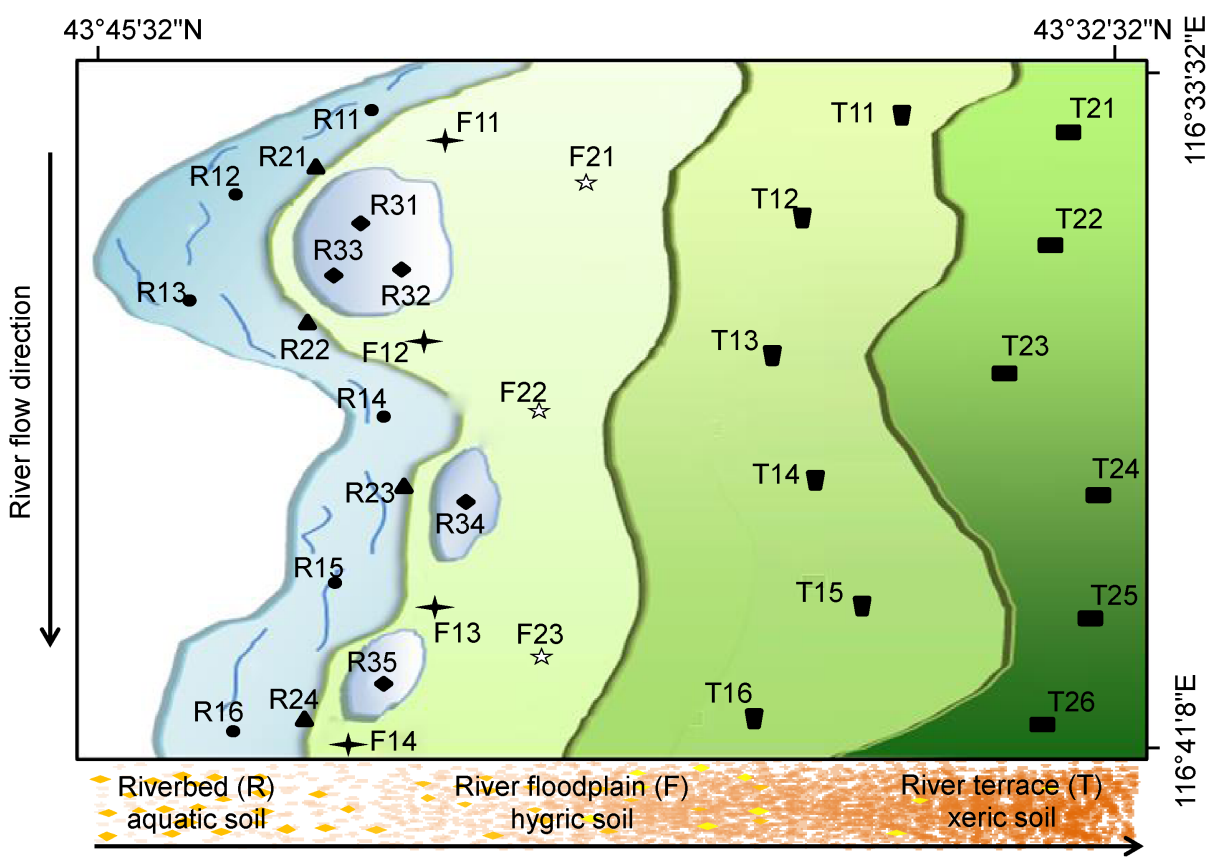

Lateral movement of water

Fig. 1 The riverbed center-riverbed edge-oxbow lake-floodplain-terrace continuum (i.e., landward distribution) of the Xilin River basin, Inner Mongolia Plateau, China. Sampling zones along a geomorphological gradient from the riverbed center (R1), riverbed edge (R2), oxbow lake (R3), low floodplain (F1), upper floodplain (F2), low terrace (T1) to the upper terrace (T2). Light blue represens aquatic habitats, light green represens hygric habitats, and deep green represents xeric habitats. There are 6 samples in R1 (R11, R12, R13, R14, R15 and R16). 4 samples in R2 (R21, R22, R23, and R24), 5 samples in R3 (R31, R32, R33, R34, R35), 4 samples in F1 (F11, LF2, F13, and F14), 3 samples in F2 (F21, F22, and F23), 6 samples in T1 (T11, T12, T13, T14, T15, and T16), and 6 samples in T2 (T21, T22, T23, T24, T25, and T26).
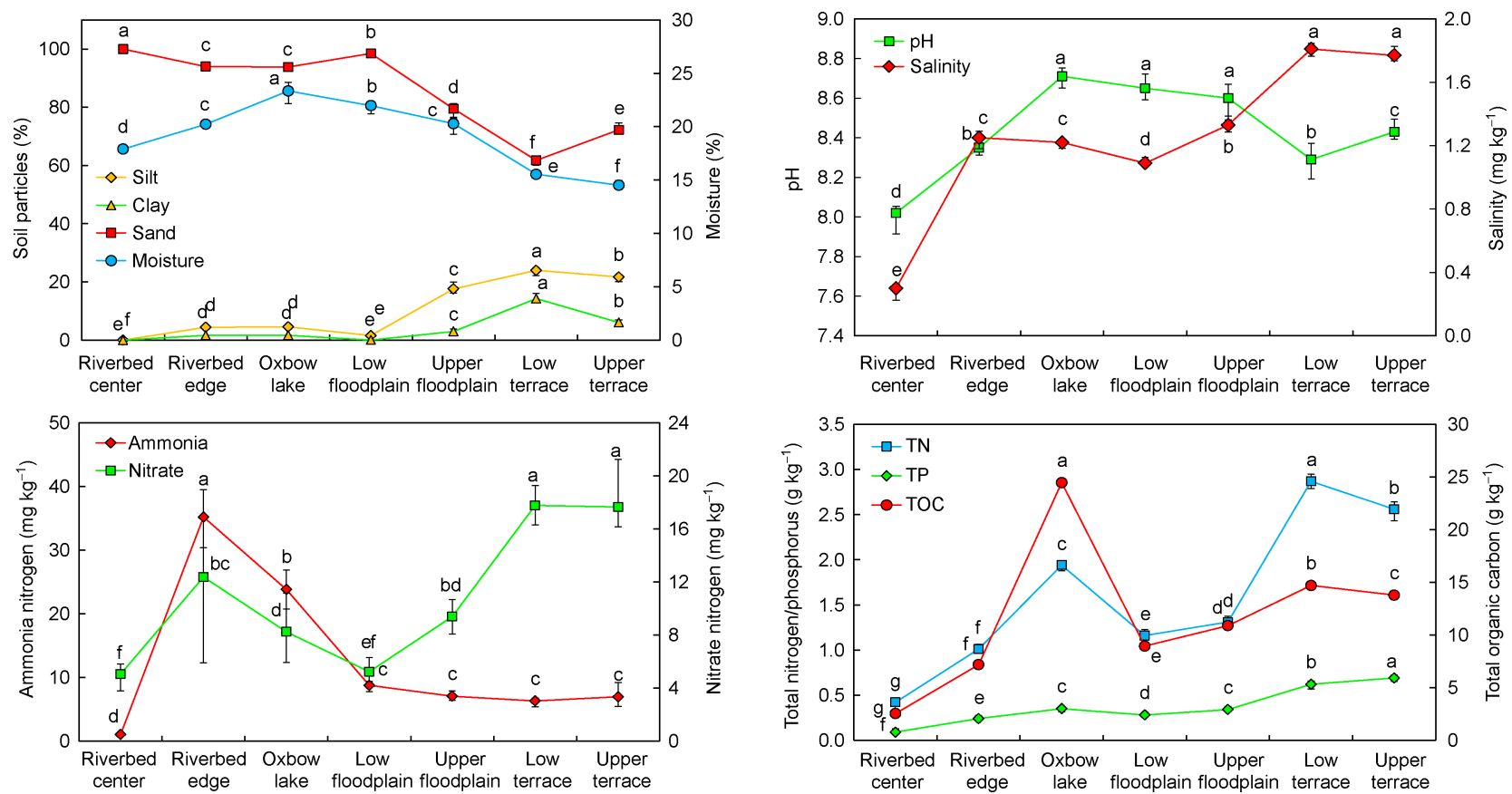

Fig. 2 Physicochemical parameters of the topsoil (0-10 cm layer) in the riverbed center (R1), riverbed edge (R2), oxbow lake (R3), low floodplain (F1), upper floodplain (F2), low terrace (T1), and the upper terrace (T2). Different lowercase letters indicate significant differences $(P<0.05)$ in physicochemical parameters among sampling zones, based on one-way analysis of variance (ANOVA). 
edge and the river terrace (Fig. 3A). The $\beta$-diversity was also different among sites (adonis, $R^{2}=0.99, P<0.05$ ) (Table S3 and Fig. 3B-3D).

The riverbed center and the oxbow lake were dominated by lineages of Bacteroidetes and Firmicutes (Fig. 4). The riverbed edge was dominated by lineage of Chloroflexi. The floodplains were dominated by lineages of Bacteroidetes, $\beta$ Proteobacteria, and Gammaproteobacteria. The terraces were dominated by lineages of Acidobacteria, Actinobacteria, Verrucomicrobia, Gemmatimonadetes, and a-Proteobacteria. Subgroup_6 of Acidobacteria increased from $0.22 \pm 0.02 \%$ in the riverbed edge to $9.77 \pm 1.06 \%$ in the upper terrace, while vadinHA17 of Bacteroidetes decreased from $8.73 \pm 1.05 \%$ in the riverbed edge to under the detection levels in the terraces (Table S4).
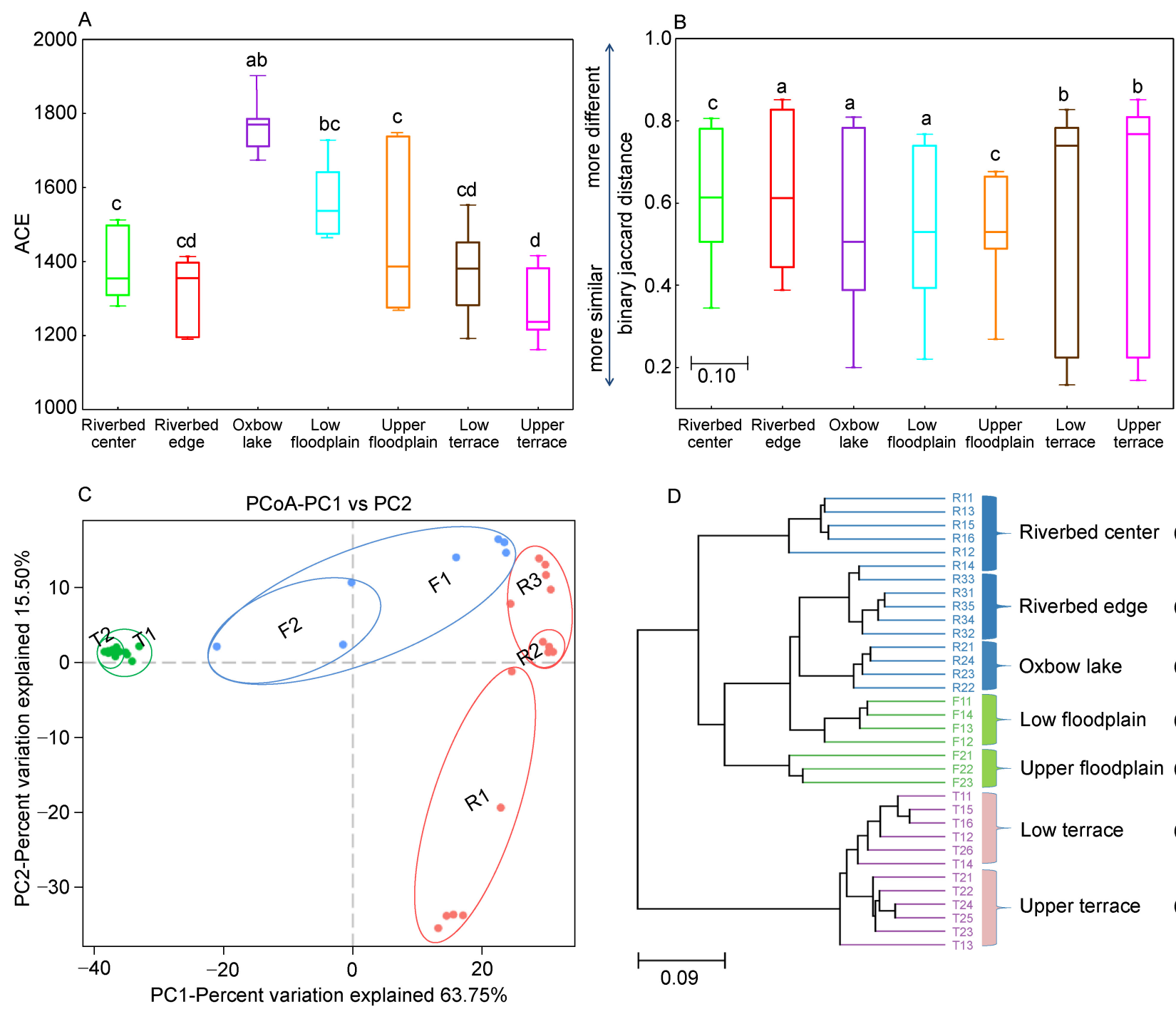

3.3 Relationship between bacteria communities and environmental variables

Six environmental variables, i.e., silt, salinity, ammonia, moisture, TOC, and $\mathrm{pH}$, were correlated with bacterial communities (RDA, $P<0.05$, Fig. $5 \mathrm{~A}$ ), with an explanatory power of $46.3 \%$ for silt, $16.6 \%$ for salinity, $7.4 \%$ for ammonia, and $7.0 \%$ for moisture. Subsequently, the six environmental variables (Fig. 5B) were divided into Group I (silt and salinity), Group II (moisture and TOC), and Group III (pH and ammonia) using random forest analysis (RFA). Group I contributed to $14.6 \%$ of bacterial community variance, Group II contributed to $6.9 \%$ of bacterial community variance, and Group III contributed to $7.7 \%$ of bacterial community variance (VPA, Fig. 5C). Their interactive effects were substantial, as Group I

Fig. 3 Comparison of the alpha-diversity $(A)$ and beta-diversity $(B, C, D)$ of bacterial communities based on the phylogenetic distance among OTUs. Different lowercase letters indicate significant differences (Student's $t$-test). ACE index was used to estimate the alphadiversity based on the number of OTUs in the community $(A)$. The horizontal line and box in boxplots indicate the median value, the upper and lower quartiles of the data, respectively $(B)$. Herein, $C$ and $D$ represent unweighted_unifrac principal coordinates analyses (PCoA) and the unweighted pair group method with arithmetic averages (UPGMA) clustering, respectively. 

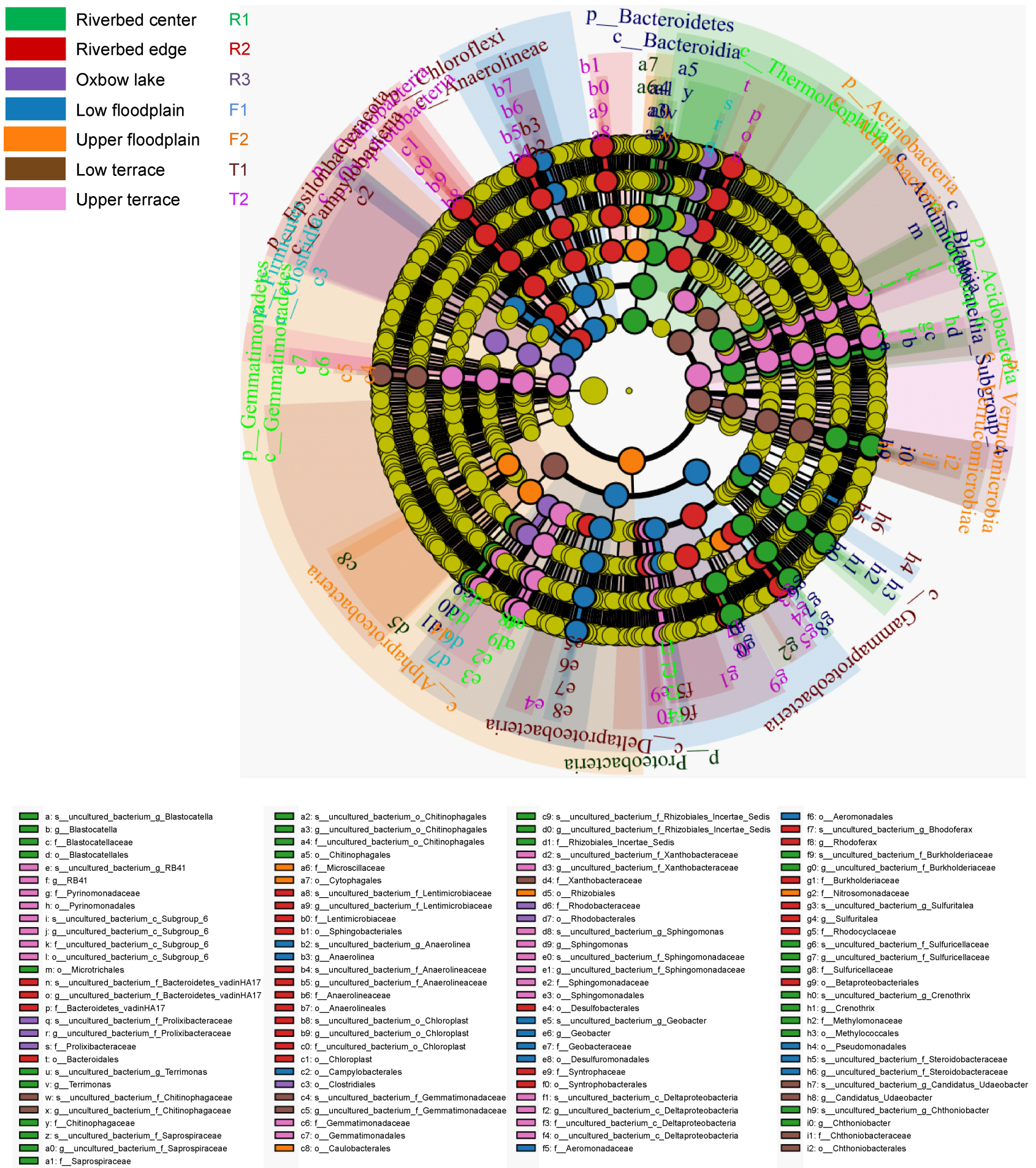

Fig. 4 A cladogram showing phylogenetic distribution of the bacterial lineages in the riverbed center (R1)-riverbed edge (R2)-oxbow lake (R3)-low floodplain (F1)-upper floodplain (F2)-low terrace (T1)-upper terrace (T2) continuum. Abundant taxa are colored by green (riverbed center), red (riverbed edge), purple (oxbow lake), blue (low floodplain), orange (upper floodplain), brown (low terrace), and pink (upper terrace), while insignificantly abundant taxa among sampling zones were colored by yellow. The diameter per circle is proportional to the taxon's relative abundance. The hierarchical analysis is non-strict (at least a taxonomic level is differential). The circles from inside to outside represent phylum $(p)$, class $(c)$, order $(o)$, family $(f)$, genus $(g)$, and species $(s)$. Labels are shown at the phylum and class levels. 
and Group II variables interactively contributed to $37.0 \%$ of bacterial community variance, suggesting that moisture is related to silt and salinity in affecting bacterial communities.

\section{Discussion}

The spatial heterogeneity of bacterial communities is clear. Consistent with previous studies in terrestrial habitats (Daebeler et al., 2014; Ranjan et al., 2015; Stempfhuber et al., 2016; Vieira et al., 2017; Huber and Overmann, 2018), DA101 of Verrucomicrobia, Subgroup 6 of Acidobacteria, Sphingomonas of a-Proteobacteria and Mycobacterium of Actinobacteria, Gemmatimonadaceae of Gemmatimonadetes and Haliangium of $\delta$-Proteobacteria were mainly present in the xeric river terrace (Table S4). In contrast, Chitinophagaceae and vadinHA17 of Bacteroidetes, Comamonadaceae of $\beta$-Proteobacteria, and Chthoniobacter of Verrucomicrobia were abundant in the riverbed (Table S4), suggesting that many bacteria are niche partitioned (Hahn et al., 2010; Freitas et al., 2012). The differences among the riverbed, floodplain, and terrace were higher than those among the riverbed center, riverbed edge, and oxbow lake (Fig. 3), revealing distinc aquatic-hygric-xeric habitats attributable to moisturerelated factors. These results are consistent with previous studies in dry ecosystems along a precipitation gradient (16$566 \mathrm{~mm} \mathrm{yr}^{-1}$ ) in northern China that the geographic variation of soil bacterial communities attributed to habitat-specific aridity in Gobi and deserts, precipitation in desert steppes, and soil inorganic nitrogen in grasslands (Su et al., 2020).

Hydrologic linkages of matter and energy within landscapes are important regulators of physical, biogeochemical, and biological processes (Amoros and Bornette, 2002). In the present study, specific bacterial taxa had a preference for given particles. For example, Comamonadaceae, Nitrosomonadaceae, Flavobacterium, and Xanthomonadales preferred
A

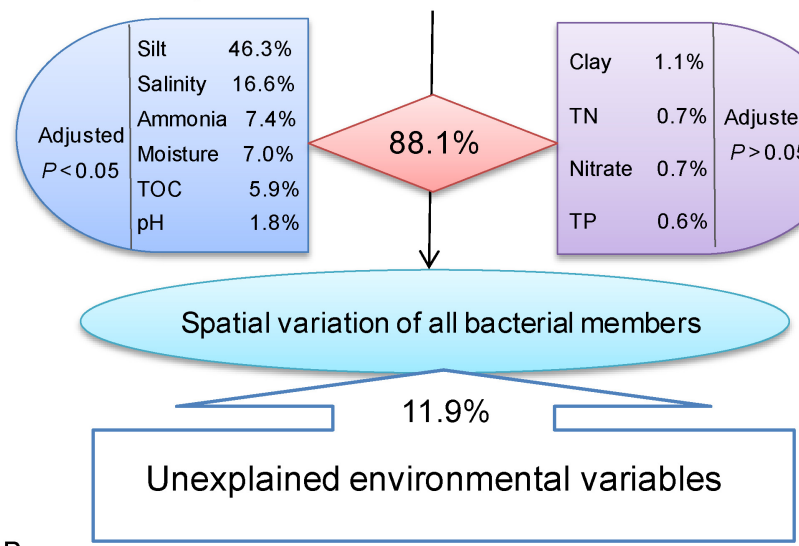

C

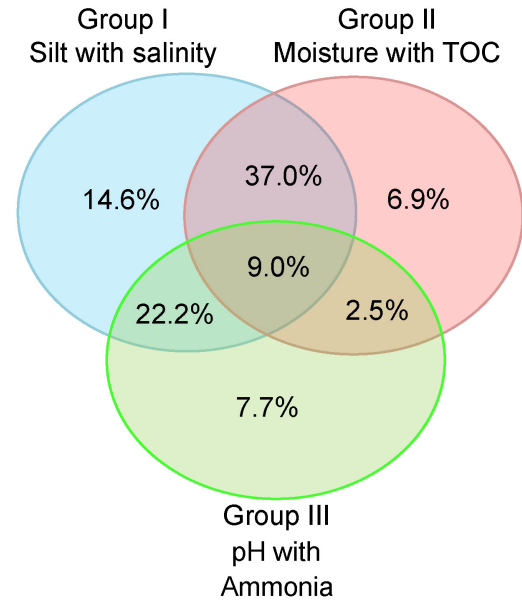

\begin{tabular}{|c|c|c|c|c|c|c|c|c|c|c|c|c|c|c|c|c|c|c|c|c|c|c|c|c|c|}
\hline & \multicolumn{5}{|c|}{ Actinobacteria } & \multicolumn{5}{|c|}{ Alphaprote obacteria } & \multicolumn{5}{|c|}{ Acidobacteria } & \multicolumn{5}{|c|}{ Bacteroidetes } & \multicolumn{5}{|c|}{ Gemmatimonadetes } \\
\hline & D 1 & ② & Q 3 & D 4 & อ 5 & D 1 & D2 & D 3 & D 4 & อ 5 & घ 1 & ② & D 3 & D 4 & D 5 & D 1 & D2 & D 3 & D 4 & อ 5 & 1 & D2 & D 3 & D 4 & D 5 \\
\hline Silt & 0.9716 & 0.9712 & 0.9693 & 0.9693 & 0.9691 & 0.9527 & 0.9524 & 0.9515 & 0.9513 & 0.9510 & 0.9493 & 0.9485 & 0.9484 & 0.9474 & 0.9471 & 0.9414 & 0.9392 & 0.9379 & 0.9375 & 0.9358 & 0.9279 & 0.9277 & 0.9258 & 0.9234 & 0.9229 \\
\hline Salinity & 0.9716 & 0.9712 & 0.9693 & 0.9693 & 0.9691 & & 0.9524 & 0.9515 & 0.9513 & 0.9510 & 0.9493 & 0.9485 & 0.9484 & 0.9474 & & 0.9414 & 0.9392 & & & 0.9358 & & 0.9277 & 0.9258 & 0.9234 & \\
\hline Moisture & 0.9716 & 0.9712 & 0.9693 & & & 0.9527 & & 0.9515 & & 0.9510 & & 0.9485 & 0.9484 & & 0.9471 & 0.9414 & 0.9392 & 0.9379 & 0.9375 & 0.9358 & & & & & \\
\hline TOC & & & 0.9693 & 0.9693 & & & & 0.9515 & 0.9513 & & & & & & & & & & & 0.9358 & & 0.9277 & & 0.9234 & \\
\hline $\mathrm{pH}$ & & 0.9712 & 0.9693 & 0.9693 & & & & & & & & & & 0.9474 & & & 0.9392 & 0.9379 & & 0.9358 & & & & 0.9234 & $\begin{array}{l}0.9229 \\
\end{array}$ \\
\hline \multirow[t]{3}{*}{ Ammonia } & & & & & & & & 0.9515 & 0.9513 & 0.9510 & & 0.9485 & & 0.9474 & & & & & & & 0.9279 & 0.9277 & 0.9258 & 0.9234 & \\
\hline & \multicolumn{5}{|c|}{ Chloroflexi } & \multicolumn{5}{|c|}{ Deltaproteobacteria } & \multicolumn{5}{|c|}{ Firmicutes } & \multicolumn{5}{|c|}{ Gammaproteobacteria } & \multicolumn{5}{|c|}{ Verrucomicrobia } \\
\hline & Q 1 & Q 2 & D 3 & D 4 & D 5 & D 1 & a 2 & D 3 & D 4 & D 5 & D 1 & Q2 & D 3 & อ 4 & D 5 & 口 1 & a 2 & D 3 & a 4 & อ 5 & D 1 & D2 & व 3 & D 4 & D 5 \\
\hline Silt & 0.9239 & 0.9232 & 0.9214 & 0.9212 & 0.9205 & 0.9125 & 0.9095 & 0.9086 & 0.9071 & 0.9070 & 0.8941 & 0.8762 & & 0.8676 & 0.8668 & 0.8802 & 0.8793 & 0.8765 & & 0.8730 & 0.8461 & 0.8258 & 0.8249 & 0.8114 & 0.8090 \\
\hline Salinity & 0.9239 & 0.9232 & & & 0.9205 & 0.9125 & & 0.9086 & 0.9071 & & 0.8941 & & 0.8718 & 0.8676 & 0.8668 & 0.8802 & & & & 0.8730 & & & & & \\
\hline Moisture & 0.9239 & 0.9232 & 0.9214 & 0.9212 & 0.9205 & & & & 0.9071 & 0.9070 & & & & 0.8676 & & & & 0.8765 & & 0.8730 & & 0.8258 & 0.8249 & 0.8114 & 0.8090 \\
\hline TOC & & & & & 0.9205 & & & & & & & & & & & & & 0.8765 & 0.8758 & 0.8730 & & & & 0.8114 & \\
\hline $\mathrm{pH}$ & 0.9239 & & 0.9214 & & & 0.9125 & 0.9095 & 0.9086 & 0.9071 & 0.9070 & & & & & & & & & & & & & 0.8249 & 0.8114 & \\
\hline Ammonia & & & & & & 0.9125 & & & 0.9071 & 0.9070 & & & & & 0.8700 & 0.8802 & 0.8793 & & & 0.8730 & 0.8461 & 0.8258 & 0.8249 & & \\
\hline
\end{tabular}

Fig. 5 Individual and combined environmental variables from constrained ordination diagram of redundancy analysis (RDA) (A), random forest analysis (RFA) (B), and based on variation partitioning analysis (VPA) of environmental variables divided into Group I (Silt and salinity), Group II (Moisture and TOC), and Group III (pH and Ammonia) (C). Adjust $P$-values in (A) were determined by Monte-Carlo test. Each row in (B) represents an environmental variable. The numbers from 1 to 5 per dominant bacterial community in the second row represent the correlation coefficient from high to low. The plaque indicates environmental factors in the combinations. The correlation coefficient decreases gradually from red yellow to green. Each column from left to right represents a combination related to each dominant bacterial community, i.e., the correlation coefficient decreases gradually from red on the left to green on the right (B). 
sand particles, while Gemmatimonadaceae, Mycobacterium, Cyanobacteria, Sphingomonas, Acetobacteraceae, Arenimonas, and Singulisphaera preferred silt and clay particles. Such findings suggest that soil particle fractions (clay, silt, and sand) might play a primary role in shaping the bacterial community compositions (Sessitsch et al., 2001; Hemkemeyer et al., 2015; Fox et al., 2018; Hemkemeyer et al., 2018).

Particle size and fractions (sand, silt, and clay) also play an important role in shaping bacterial communities, sometimes more important than nutrient status (Sessitsch et al., 2001; Hemkemeyer et al., 2015; Fox et al., 2018; Hemkemeyer et al., 2018). It was shown that larger particle sizes were dominated by $\alpha$-Proteobacteria, whereas smaller size fractions were dominated by Acidobacterium (Sessitsch et al., 2001). Since the silt particle showed the highest contribution (46.3\%) to bacterial community compositions (Fig. $5 \mathrm{~A}$ ), silt particle might be a proximal "control lever" in shaping soil bacterial communities, as observed elsewhere (Jeng et al., 2005; Wu et al., 2012; Pasternak et al., 2013; Ranjard et al., 2013; Wang et al., 2014; Fox et al., 2018). A possible reason is that the silt particle at the interface between sand and clay particles regulates the capillary and non-capillary porosity and balances sand's water-permeability and clay's water-holding capacity, further influencing adsorption and desorption of nutrient ions and other physicochemical factors (Reddy et al., 2010). This is consistent with our results that silt particle was strongly correlated with contents of clay, sand, salinity, TP, TOC, TN, nitrate, and moisture ( $P<0.05$, Table S5) except pH and ammonia. Macro-aggregates $(>250 \mu \mathrm{m})$ originating from coarse silt and sand particles provide a suitable habitat for free-living bacteria. In contrast, micro-aggregates $(<250 \mu \mathrm{m})$ rich in fine silt and clay particles provide suitable habitats for particle-attached bacteria (Kristiansen et al., 2006). Notably, silt particle at the interface between sand and clay particles might play a decisive role in the formation of aggregates (Table S1), further influencing the physicochemical characteristics and bacterial communities (Jeng et al., 2005; Wu et al., 2012; Hemkemeyer et al., 2018). For example, the silt particles $(5-53 \mu \mathrm{m})$ accounted for $80 \%$ of Escherichia coli attachment (Jeng et al., 2005; Wu et al., 2012), while the silt particles represented possible hotspots for nitrification driven by Nitrosomonadales and Nitrospiraceae (Hemkemeyer et al., 2018).

Salinity plays major roles in affecting aquatic bacterial communities (Campbell and Kirchman, 2013; Shen et al., 2018). Here, salinity was an important factor influencing bacterial communities across aquatic-hygric-xeric habitats (Fig. 5A). A possible reason was that salinity drove bacterial tolerance to rewetting and drying (Baumann and Marschner, 2013). Alternatively, ion-base exchange capacity was mainly associated with medium-sized silt fractions and fine clay and coarse sand particle sizes (Xia et al., 2018). Therefore, salinity associated with exchangeable cations interacts with soil particle size in affecting bacterial communities. Moisture is also related to soil particle size (Reddy et al., 2010). In contrast, $\mathrm{pH}$ plays an important but relatively minor role in affecting bacterial communities (Fig. 5). In addition to several soil variables selected in this study, vegetation and other factors (e.g. the formation process of spatial pattern) are also important determinants (Shi et al., 2020).

The water depth plays a key role in shaping aquatic bacterial communities (Shen et al., 2012; Cui et al., 2019). Here, the water depth could drive the difference of bacterial diveristy among the aquatic riverbed center $(0.25-0.45 \mathrm{~m})$, riverbed edge $(0.45-0.65 \mathrm{~m})$, and oxbow lake $(0.55-0.85 \mathrm{~m})$. A possible reason is that the water depth affects the separation of soil particles and further drives the differentiation of free-living and particle-associated bacterial communities (Cui et al., 2019).

\section{Concluding remarks and future perspectives}

In a nutshell, our results demonstrate that the silt particle and moisture-related factors are influential for soil bacterial communities in the riverside landscape. Along the lateral riverside continuum from the riverbed center-riverbed edgeoxbow lake-floodplain-terrace (i.e., landward distribution), the lineage of $y$-Proteobacteria (e.g., Xanthomonadales) first increased and then decreased, reaching the peak value of the relative abundance in the floodplain, while those of Acidobacteria (e.g., Subgroup_6), Verrucomicrobia (e.g., DA101 soil_group), a-Proteobacteria (e.g., Sphingomonas) and Actinobacteria (e.g., Mycobacterium) lineages gradually increased and reached the peak value in the river terrace. As climate changes inevitably affect bacterial soil communities, it is likely to predict how soil bacterial communities will be shifted under future climate scenarios. Conversely, changes in bacterial communities might serve as early indicators of environmental changes, particularly when there are shifts among aquatic-hygric-xeric habitats.

Our study shows that soil particles and moisture-related environment factors determine bacterial communities in a lateral riverside continuum of the Xilin River Basin. Soils at the multiple interfaces of the lithosphere-hydrosphere- atmosphere-biosphere harbor a high bacterial diversity, which is influenced by many factors, such as the vegetation and landuse types (e.g., grazing intensity in the Xilin River Basin) in addition to environmental factors. It will be essential to understand how belowground microorganisms, aboveground vegetations, and other factors influence soil bacterial variables along the lateral or vertical river landscape continuum. We need to further explore the edaphic and biohydrological processes characterizing a river landscape continuum in the future.

\section{Acknowledgments}

This work was supported financially by the National Natural Science Foundation of China to J. Yu (41361053), X. Tanggood (31660724) and Y. Yang (41825016), the Natural Science Foundation of Inner Mongolia to J. Yu (2011MS0603, 
2016MS0331) and X. Tanggood (2015MS0306), and the National College Students Innovation and Entrepreneurship Training Program of Inner Mongolia University to C.H. Li, X. Li, W.Z. Wu, W. Dong and Y. Jia (201810126043). The authors thank Huhe, G. Feng, Y. Lu, S.H. Zhang, Z.C. Zhang, Y.B. Shi, Z.Y. Li, W. Wang, Z.H. Bao, and H. Qing from Inner Mongolia University and R.X. Zhao from Tsinghua University for assistance in bioinformatics analysis.

\section{Electronic supplementary material}

Supplementary material is available in the online version of this article at https://doi.org/10.1007/s42832-021-0106-2 and is accessible for authorized users.

\section{References}

Amoros, C., Bornette, G., 2002. Connectivity and biocomplexity in waterbodies of riverine floodplains. Freshwater Biology 47, 517 539.

Bai, Y.F., Li, L.H., Wang, Q.B., Zhang, L.X., Zhang, Y., Chen, Z.Z., 2000. Changes in plant species diversity and productivity along gradients of precipitation and elevation in the Xilin River Basin, Inner Mongolia. Acta Phytoecologica Sinica 24, 667-673.

Baumann, K., Marschner, P., 2013. Effects of salinity on microbial tolerance to drying and rewetting. Biogeochemistry 112, 71-80.

Bracken, L.J., Wainwright, J., Ali, G.A., Tetzlaff, D., Smith, M.W., Reaney, S.M., Roy, A.G., 2013. Concepts of hydrological connectivity: research approaches, pathways and future agendas. Earth-Science Reviews 119, 17-34.

Campbell, B.J., Kirchman, D.L., 2013. Bacterial diversity, community structure and potential growth rates along an estuarine salinity gradient. ISME Journal 7, 210-220.

Cui, Y., Chun, S.J., Baek, S.H., Lee, M., Kim, Y., Lee, H.G., Ko, S.R., Hwang, S., Ahn, C.Y., Oh, H.M., 2019. The water depth-dependent co-occurrence patterns of marine bacteria in shallow and dynamic Southern Coast, Korea. Scientific Reports 9, 9176.

Daebeler, A., Bodelier, P.L., Yan, Z., Hefting, M.M., Jia, Z., Laanbroek, H.J., 2014. Interactions between Thaumarchaea, Nitrospira and methanotrophs modulate autotrophic nitrification in volcanic grassland soil. ISME Journal 8, 2397-2410.

Fierer, N., Jackson, R.B., 2006. The diversity and biogeography of soil bacterial communities. Proceedings of the National Academy of Sciences of the United States of America 103, 626-631.

Fierer, N., Leff, J.W., Adams, B.J., Nielsen, U.N., Bates, S.T., Lauber C.L., Owens, S., Gilbert, J.A., Wall, D.H., Caporaso, J.G., 2012. Cross-biome metagenomic analyses of soil microbial communities and their functional attributes. Proceedings of the National Academy of Sciences of the United States of America 109, 21390-21395.

Fox, A., Ikoyi, I., Torres-Sallan, G., Lanigan, G., Schmalenberger, A., Wakelin, S., Creamer, R., 2018. The influence of aggregate size fraction and horizon position on microbial community composition. Applied Soil Ecology 127, 19-29.

Freitas, S., Hatosy, S., Fuhrman, J.A., Huse, S.M., Welch, D.B., Sogin, M.L., Martiny, A.C., 2012. Global distribution and diversity of marine Verrucomicrobia. ISME Journal 6, 1499-1505.

Gay, A., Cerdan, O., Mardhel, V., Desmet, M., 2016. Application of an index of sediment connectivity in a lowland area. Journal of Soils and Sediments 16, 280-293.

Hahn, M.W., Kasalický, V., Jezbera, J., Brandt, U., Jezberová, J., Šimek, K., 2010. Limnohabitans curvus gen. nov., sp. nov., a planktonic bacterium isolated from a freshwater lake. International Journal of Systematic and Evolutionary Microbiology 60, 13581365.

Hemkemeyer, M., Christensen, B.T., Martens, R., Tebbe, C.C., 2015. Soil particle size fractions harbour distinct microbial communities and differ in potential for microbial mineralisation of organic pollutants. Soil Biology \& Biochemistry 90, 255-265.

Hemkemeyer, M., Dohrmann, A.B., Christensen, B.T., Tebbe, C.C., 2018. Bacterial preferences for specific soil particle size fractions revealed by community analyses. Frontiers in Microbiology 9, 149.

Huber, K.J., Overmann, J., 2018. Vicinamibacteraceae fam. nov., the first described family within the subdivision 6 Acidobacteria. International Journal of Systematic and Evolutionary Microbiology 68, 2331-2334.

Jeng, H.C., England, A.J., Bradford, H.B., 2005. Indicator organisms associated with stormwater suspended particles and estuarine sediment. Journal of Environmental Science and Health. Part A, Toxic/Hazardous Substances \& Environmental Engineering 40, 779-791.

Kristiansen, S.M., Schjonning, P., Thomsen, I.K., Olesen, J.E., Kristensen, K. and Christensen, B.T., 2006. Similarity of differently sized macro-aggregates in arable soils of different texture. Geoderma 137, 147-154.

Leibowitz, S.G., Wigington, P.J. Jr, Schofield, K.A., Alexander, L.C., Vanderhoof, M.K., Golden, H.E., 2018. Connectivity of streams and wetlands to downstream waters: an integrated systems framework. Journal of the American Water Resources Association 54, 298-322.

Pasternak, Z., Al-Ashhab, A., Gatica, J., Gafny, R., Avraham, S., Minz, D., Gillor, O., Jurkevitch, E., 2013. Spatial and temporal biogeography of soil microbial communities in arid and semiarid regions. PLoS One 8, e69705.

Ranjan, K., Paula, F.S., Mueller, R.C., Jesus, Eda.C., Cenciani, K., Bohannan, B.J., Nüsslein, K., Rodrigues, J.L., 2015. Forest-topasture conversion increases the diversity of the phylum Verrucomicrobia in Amazon rainforest soils. Frontiers in Microbiology 6 , 779.

Ranjard, L., Dequiedt, S., Chemidlin Prévost-Bouré, N., Thioulouse, J., Saby, N.P., Lelievre, M., Maron, P.A., Morin, F.E., Bispo, A., Jolivet, C., Arrouays, D., Lemanceau, P., 2013. Turnover of soil bacterial diversity driven by wide-scale environmental heterogeneity. Nature Communications 4, 1434.

Reddy, S., Shashidhar, K.S., Vinoda, K.S., Chandrashekara, C., Gowda, R.C., 2010. Effect of tank silt on physico-chemical properties of soil with fingermillet crop in eastern dry zone of Karnataka. Environment and Ecology 28, 1424-1427.

Sessitsch, A., Weilharter, A., Gerzabek, M.H., Kirchmann, H., Kandeler, E., 2001. Microbial population structures in soil particle size fractions of a long-term fertilizer field experiment. Applied and Environmental Microbiology 67, 4215-4224. 
Shen, C.C., Xiong, J.B., Zhang, H.Y., Feng, Y.Z., Lin, X.G., Li, X.Y., Liang, W.J., Chu, H.Y., 2013. Soil pH drives the spatial distribution of bacterial communities along elevation on Changbai Mountain. Soil Biology \& Biochemistry 5, 204-211.

Shen, D., Jürgens, K., Beier, S., 2018. Experimental insights into the importance of ecologically dissimilar bacteria to community assembly along a salinity gradient. Environmental Microbiology 20, 1170-1184.

Shen, L., Yao, T., Xu, B., Wang, H., Jiao, N., Kang, S., Liu, X., Liu, Y., 2012. Variation of culturable bacteria along depth in the east rongbuk ice core, mt. everest. Geoscience Frontiers 3, 327-334.

Shi, Y.B., Su, C., Wang, X.L., Liu, X.L., Liang, C.Z., Zhao, L.Q., Zhang, X.Y., Minggagud, H., Feng, G., Ma, W.H., 2020. Modern climate and soil properties explain functional structure better than phylogenetic structure of plant communities in northern China. Frontiers in Ecology and Evolution 8, 531947.

Stempfhuber, B., Richter-Heitmann, T., Regan, K.M., Kölbl, A., Wüst, P.K., Marhan, S., Sikorski, J., Overmann, J., Friedrich, M.W., Kandeler, E., Schloter, M., 2016. Spatial interaction of archaeal ammonia-oxidizers and nitrite-oxidizing bacteria in an unfertilized grassland soil. Frontiers in Microbiology 6, 1567.

Su, Y.G., Liu, J., Zhang, B.C., Zhao, H.M., Huang, G., 2020. Habitatspecific environmental factors regulate spatial variability of soil bacterial communities in biocrusts across northern China's drylands. Science of the Total Environment 719, 137479.

Tong, C., Wu, J., Yong, S., Yang, J., Yong, W., 2004. A landscapescale assessment of steppe degradation in the Xilin River Basin, Inner Mongolia, China. Journal of Arid Environments 59, 133-149.

Vieira, S., Luckner, M., Wanner, G., Overmann, J., 2017. Luteitalea pratensis gen. nov., sp. nov. a new member of subdivision 6 Acidobacteria isolated from temperate grassland soil. International
Journal of Systematic and Evolutionary Microbiology 67, 1408 1414.

Wang, L., Zheng, B., Nan, B., Hu, P., 2014. Diversity of bacterial community and detection of nirS- and nirK-encoding denitrifying bacteria in sandy intertidal sediments along Laizhou Bay of Bohai Sea, China. Marine Pollution Bulletin 88, 215-223.

Wang, P., Chen, B., Zhang, H., 2017. High throughput sequencing analysis of bacterial communities in soils of a typical Poyang Lake wetland. Acta Ecologica Sinica 5, 1650-1658.

Weese, J.S., Jalali, M., 2014. Evaluation of the impact of refrigeration on next generation sequencing-based assessment of the canine and feline fecal microbiota. BMC Veterinary Research 10, 230.

Wu, G., Xue, H., Liu, T., 2021. Change characteristics and trends of precipitation and average temperature in the Xilinhe River Basin from 1961 to 2016. Arid Land Geography doi:65.1103. X.20210323.1728.006.

Wu, H., Jiang, D., Cai, P., Rong, X., Dai, K., Liang, W., Huang, Q., 2012. Adsorption of Pseudomonas putidaon soil particle size fractions: effects of solution chemistry and organic matter. Journal of Soils and Sediments 12, 143-149.

Xia, H., Kong, W., Li, X., Fan, J., Guo, F., Sun, O.J., 2018. Lateral heterogeneity of soil physicochemical properties in riparian zones after agricultural abandonment. Scientific Reports 8, 2228.

Yang, Y., Wu, L., Lin, Q., Yuan, M., Xu, D., Yu, H., Hu, Y., Duan, J., Li, X., He, Z., Xue, K., van Nostrand, J., Wang, S., Zhou, J., 2013. Responses of the functional structure of soil microbial community to livestock grazing in the Tibetan alpine grassland. Global Change Biology 19, 637-648.

Zhang, K., Shi, Y., Cui, X., Yue, P., Li, K., Liu, X., Tripathi, B.M., Chu, H., 2019. Salinity is a key determinant for soil microbial communities in a desert ecosystem. mSystems 4, e00225-e18. 